\title{
The Function of the $\beta$-Ketoadipate Pathway in Pseudomonas acidovorans
}

\author{
By MALKA ROBERT-GERO, MARYSE POIRET \\ AND R. Y. STANIER* \\ Centre de Recherches Hydrobiologiques, C.N.R.S., \\ 9I- Gif sur Yvette, France
}

(Accepted for publication 28 March 1969)

\begin{abstract}
SUMMAR Y
Aerobic enrichment at $30^{\circ}$ in a medium containing either cis, cis- or cis,transmuconic acid as the sole source of carbon and energy is a highly specific method for the isolation of Pseudomonas acidovorans from soil. Nutritional studies with previously isolated strains of $P$. acidovorans and $P$. testosteroni, none of which was selected for the ability to utilize muconates, show that nearly all strains of both these species grow readily and promptly with both cis isomers of muconic acid. This ability is absent from all fluorescent pseudomonads examined, despite the fact that they possess the requisite enzymic machinery. The fluorescent pseudomonads appear to be impermeable to the muconic acids, and can use them as substrates for growth only through a mutation that alters the permeability of the cell.

Studies with one strain of Pseudomonas acidovorans show that it synthesizes inducibly all the enzymes responsible for the conversion of catechol to $\beta$ ketoadipate, their synthesis being elicited by growth with either cis,cis- or cis,trans-muconate. Mutants of $P$. acidovorans defective in the synthesis of either $\beta$-ketoadipate enol-lactone hydrolase or $\beta$-ketoadipate succinyl-CoA transferase are unable to grow at the expense of cis,cis-or cis,trans-muconate; this confirms the role of the $\beta$-ketoadipate pathway in the dissimilation of these two substrates by $P$. acidovorans.
\end{abstract}

\section{INTRODUCTION}

Aerobic bacteria belonging to many taxonomic groups dissimilate such aromatic and hydroaromatic compounds as benzoic acid, p-hydroxybenzoic acid, phenol, tryptophan, quinic acid and shikimic acid through one of the convergent branches of the $\beta$-ketoadipate pathway (Fig. I). The $\beta$-ketoadipate pathway is the commonest, but not the sole, biochemical route for the oxidation of such primary substrates. In the genus Pseudomonas, where this pathway is used by most species capable of oxidizing aromatic and hydroaromatic compounds, two species-Pseudomonas acidovorans and $P$. testosteroni-dissimilate these compounds through entirely different metabolic pathways (Stanier, Hayaishi \& Tsuchida, I95I; Stanier, Palleroni \& Doudoroff, 1966; Wheelis, Palleroni \& Stanier, 1967). Since the $\beta$-ketoadipate pathway is not known to operate in the dissimilation of any other class of primary substrates, it appeared to be absent from $P$. acidovorans and $P$. testosteroni. We have now found that this assumption is incorrect. $P$. acidovorans can synthesize inducibly many of the

* Present address: Department of Bacteriology and Immunology, University of California, Berkeley, California, U.S.A. 
enzymes in the pathway, which function in the dissimilation of muconic acids by this species.

Cis,cis-muconic acid is an intermediate in the catechol branch of the $\beta$-ketoadipate pathway (Fig. I). However, bacteria that use the $\beta$-ketoadipate pathway are characteristically impermeable to cis,cis-muconic acid, being unable either to respire it or

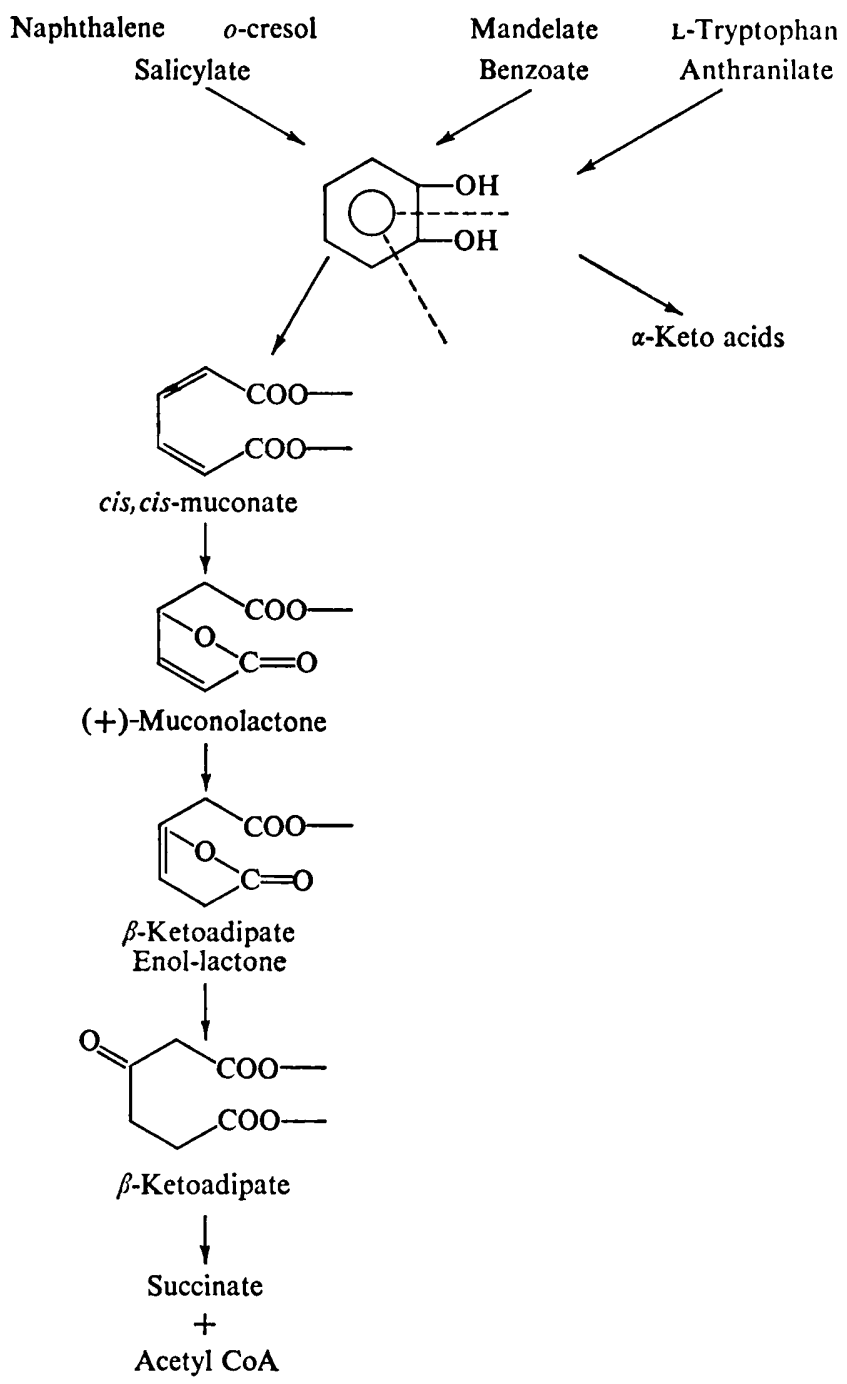

Fig. 1. Metabolic map showing dissimilation of aromatic compounds via catechol. Cleavage of catechol in meta position leads to $\alpha$-keto acids; ortho cleavage of cathechol gives rise to the $\beta$-ketoadipate pathway.

to use it for growth. In Pseudomonas putida (Ornston, 1966b), P. aeruginosa (Kemp \& Hegeman, 1968) and Acinetobacter (Moraxella) calcoacetica (Cánovas \& Stanier, 1967) the barrier to its use can be overcome by mutation: selection for the ability to grow with cis,cis-muconate yields rare spontaneous mutants with greatly increased 
permeability to this compound. The cis,trans isomer of muconic acid, which can be readily formed chemically from the cis,cis isomer (Elvidge, Linstead, Sims \& Orkin, 1950 a), is not known to have a metabolic role. However, Sistrom \& Stanier (1954) showed that it could be slowly converted to (-)-muconolactone by the muconate lactonizing enzyme of $P$. putida, which catalyses the reversible conversion of the cis, cis isomer to (+)-muconolactone.

The experiments described here originated from an attempt to ascertain the nature of the micro-organisms responsible for the dissimilation of muconic acids in Nature.

\section{METHODS}

Media and conditions of cultivation. All media were prepared from a basal salt solution of the following composition (g./l.): $\mathrm{NH}_{4} \mathrm{Cl}, \mathrm{I} \cdot 0 ; \mathrm{KH}_{2} \mathrm{PO}_{4}, 2 \cdot 72 ; \mathrm{Na}_{2} \mathrm{HPO}_{4}$, $2.82 ; \mathrm{MgSO}_{4}, 0.2 ; \mathrm{CaCl}_{2}, 0.05 ; \mathrm{FeSO}_{4} \cdot 7 \mathrm{H}_{2} \mathrm{O}, 0.005 ; \mathrm{Na}_{2} \mathrm{MoO}_{4} \cdot 2 \mathrm{H}_{2} \mathrm{O}, 0.00 \mathrm{I} ; \mathrm{MnSO}_{4}$, $0.00 \mathrm{I} ; \mathrm{Co}\left(\mathrm{NO}_{3}\right)_{2} .6 \mathrm{H}_{2} \mathrm{O}, 0.00 \mathrm{I}$. The organic compound serving as source of carbon and energy was added from a concentrated, sterile stock solution, to $0 . \mathrm{I} \%(\mathrm{w} / \mathrm{v})$. The final $\mathrm{pH}$ was 6.8. cis,cis-Muconate and other thermolabile substrates were sterilized by filtration. Solid media were prepared by separately sterilizing double strength mineral base and $2 \%(w / v)$ Ionagar No. 2, which were combined and supplemented with the carbon source after cooling to below $50^{\circ}$.

Stock cultures were maintained on succinate agar slopes. Liquid cultures were grown in flasks containing approximately 0.25 vol. medium, subjected to mechanical agitation, at $30^{\circ}$. Growth was determined turbidometrically in a Beckman model DK-2 A spectrophotometer at $660 \mathrm{~m} \mu$.

Enrichment experiments. Two series of shallow layers of liquid basal medium, furnished respectively with cis,cis- or cis,trans-muconic acid as sole carbon source, were inoculated with I $\mathrm{g}$. of five different soil samples and incubated at $30^{\circ}$ without agitation. After 2 or 3 days, transfers were made to fresh media of similar compositions. Isolations were made by plating on the homologous agar medium, and the predominant bacterial type from each enrichment was purified and characterized by the methods described by Stanier et al. (I966).

Isolation of mutants. Mutants of Pseudomonas acidovorans strain 13 unable to grow with muconate were prepared by treatment with $N$-methyl- $N^{\prime}$-nitro- $N$-nitrosoguanidine, using the techniques of mutagenic treatment and selection described by Ornston (1966b).

Preparation of cell-free extracts. Exponentially growing organisms were harvested from $500 \mathrm{ml}$. of medium by centrifugation at $7000 \mathrm{~g}$ for $15 \mathrm{~min}$. at $0^{\circ}$. The bacteria were washed by centrifugation in $20 \mathrm{mM}$ tris- $\mathrm{HCl}$ buffer $(\mathrm{pH} \mathrm{8.0)}$ which was $10 \mu \mathrm{M}$ in Mg-EDTA, and the pellets were resuspended in $5 \mathrm{ml}$. of the same buffer and stored at $-20^{\circ}$.

Frozen suspensions were thawed and ultrasonically disrupted (Io min. with an MSE sonic disintegrator). The probe was pre-chilled and the samples were cooled in ice during treatment. The extract was centrifuged at $100,000 \mathrm{~g}$ for $45 \mathrm{~min}$. in a Martin Christ 'Omikron' refrigerated ultracentrifuge. The supernantant fluid was used as crude extract for measurement of enzyme activities. The extracts were kept in cracked ice until all the enzymes had been assayed. Extractions and assays were generally performed on the same day. 
Enzyme assays. The following enzymes were assayed by the methods of Ornston (1966a): catechol oxygenase (E.C. I.99.2.2; catechol I,2 oxygenase); muconate lactonizing enzyme (E.C. 5.5.I.I; 4-carboxy-methyl-4-hydroxyisocrotonolactone lyase (decyclizing), recommended trivial name 'muconate cycloisomerase'); (+)muconolactone isomerase and $\beta$-ketoadipate enol-lactone hydrolase (no E.C. names). Transferase (E.C. 2.8.3.6; $\beta$-ketoadipate succinyl-CoA transferase or 3-oxoadipateCoA transferase) activity was determined by the method of Cánovas \& Stanier (I967).

All assays were performed at room temperature with a Beckman DK-2A recording spectrophotometer. With the exception of transferase activities, the unit of enzyme activity is defined as the amount of enzyme necessary to cause the disappearence of I $\mu$ mole of substrate per min. under the conditions of assay employed. Since the extinction coefficient of the product measured in transferase assays ( $\beta$-ketoadipyl-CoA) is not known, the unit of transferase activity is defined in arbitrary terms as the amount of enzyme necessary to cause a change of $\mathrm{I} \cdot 0$ (optical density) units per min. under the prescribed assay conditions.

Manometric experiments. Carbon dioxide evolution and oxygen consumption were measured in a Warburg apparatus (Braun, Model W85) at $30^{\circ}$. Exponentially growing bacteria were centrifuged and resuspended in $20 \mathrm{~mm}$-phosphate buffer $(\mathrm{pH} 7)$ at a concentration of approximately $300 \mu \mathrm{g}$. dry weight $/ \mathrm{ml}$. The main compartment of each flask contained $1.6 \mathrm{ml}$. suspension; the centre well $0.2 \mathrm{ml}$. of $\mathrm{KOH} 20 \%(\mathrm{w} / \mathrm{v})$; and the side-arm $5 \mu$ mole substrate. All data were corrected for endogenous oxygen uptake. $\beta$-Ketoadipate was quantitatively determined by catalytic decarboxylation with 4-amino-antipyrine as described by Sistrom \& Stanier (I953).

Chemical measurements. Protein concentrations were determined by the method of Lowry, Rosebrough, Farr \& Randall (I95I) with a bovine serum albumin (purchased from NBC Research Biochemicals) as standard. Lactone was determined by the hydroxamate method of Hestrin (1949). $\beta$-Ketoadipate was detected by the Rothera reaction (Rothera, I908).

Chemical syntheses. cis,cis-Muconic acid was synthesized by the method of Elvidge, Linstead, Orkin, Sims, Baer \& Pattison (1950 b). cis,trans-Muconic acid was prepared from the cis,cis isomer as described by Elvidge et al. (I950a). Racemic muconolactone ( $\lambda$-carboxymethyl- $\Delta \alpha$-butenolide) was synthesized as described by Elvidge et al. $(\mathrm{I} 950 \mathrm{~b})$. $\beta$-Ketoadipic acid was prepared by the method of Riegel \& Lilienfeld (I945). Succinyl-coenzyme A was synthesized by the method of Simon \& Shemin (I953).

\section{RESULTS}

Enrichment experiments. With different soil samples as inocula, five separate enrichment cultures in media containing cis, cis-muconate as sole source of carbon and energy all yielded one type of non-pigmented aerobic pseudomonad as the dominant organism. The same bacterium was also predominant in four out of five enrichment cultures containing cis,trans-muconate as sole source of carbon and energy. These nine strains were identified by the taxonomic criteria of Stanier et al. (1966), as Pseudomonas acidovorans. All strains grew promptly with both cis, cis- and cis,transmuconate.

Utilization of muconates for growth by Pseudomonas species. The unexpected outcome of these enrichment experiments led us to examine systematically the ability of 
Pseudomonas species to grow on muconates. Strains derived from the collection used in the taxonomic analysis of Stanier et al. (1966) were employed. No strains representative of the fluorescent groups (Pseudomonas aeruginosa, $P$. putida and $P$. fluorescens) grew immediately with either isomer of muconic acid. When growth did occur, it was delayed, and consisted of a few isolated colonies in an area of dense inoculation on muconate agar plates (Pl. I, fig. 1). Irrespective of the medium on which they arose, these clones could grow promptly with both cis,cis- and cis,trans-muconate (Pl. I, fig. 2). In the light of previous work (Ornston, I $966 a$; Kemp \& Hegeman, 1968), they can be interpreted as permeability mutants. The wild types of the fluorescent pseudomonads must accordingly possess the enzymic machinery for the dissimilation of cis,trans-muconate, as well as of the cis, cis isomer.

Parallel experiments showed that most of the strains of Pseudomonas acidovorans and $P$. testosteroni previously studied by Stanier et al. (1966) grew promptly and abundantly on both isomers of muconic acid (Pl. I, fig. I). Of the 15 strains of $P$. acidovorans, only one (strain I I4) failed to grow. Of the I I strains of $P$. testosteroni, strain 60 could not grow with either isomer, while strains 27 and 78 grew with the cis,cis, but not with the cis,trans isomer. Since none of these strains had been isolated by methods selective for the ability to dissimilate muconic acids (see Stanier et al. 1966), it follows that prompt growth on cis,cis- and cis,trans-muconic acids is an additional nutritional character that distinguishes the two species of the acidovorans group from fluorescent pseudomads. This nutritional character is not shared by the wild types of the fluorescent pseudomonads, even though they possess the necessary enzymic machinery, since all species of this generic sub-group are impermeable to muconic acids. The situation is analogous to that which exists in the members of the enteric group, with respect to the utilization of citric acid as a carbon source.

Table 1. Rates of oxygen uptake at the expense of various compounds by $P$. acidovorans strain 13

\begin{tabular}{lccccc} 
& \multicolumn{3}{c}{ Rate of oxygen uptake $(\mu \mathrm{l} / \mathrm{hr} / \mathrm{mg}$. protein $)$ with: } \\
Growth substrate & Catechol & $\begin{array}{c}\text { Cis,cis- } \\
\text { muconate }\end{array}$ & $\begin{array}{c}\text { Cis,trans- } \\
\text { muconate }\end{array}$ & $\begin{array}{c} \pm \text { Mucono- } \\
\text { lactone }\end{array}$ & $\begin{array}{c}\beta \text {-ketoadi- } \\
\text { pate }\end{array}$ \\
Succinate & 0 & $1 \mathrm{I}$ & 0 & 0 & 53 \\
Cis,cis-muconate & 248 & 489 & 146 & 232 & 466 \\
Cis,trans-muconate & 149 & 377 & 400 & 208 & 331
\end{tabular}

All data corrected for endogenous oxygen uptake.

Muconate metabolism by Pseudomonas acidovorans. One of the newly isolated strains of $P$. acidovorans, obtained by enrichment with cis,trans-muconate (strain 13), was used to study the pathway of muconate metabolism by this species. Succinategrown bacteria did not respire with either isomer of muconate at an appreciable rate. Bacteria grown with either isomer of muconate immediately respired with both isomers at high rates. These rates were equal for bacteria grown with cis, transmuconate, but the respiration with the cis,trans isomer by bacteria grown with cis,cismuconate was considerably slower than that of the cis,cis isomer. As also shown in Table I, growth with the muconates likewise induced high rates of oxidation of catechol, racemic muconolactone and $\beta$-ketoadipate. These data accordingly suggest that 
the muconates can induce all the enzymes required for the metabolism of catechol through the reactions of the $\beta$-ketoadipate pathway in $P$. acidovorans.

This conclusion was confirmed by enzyme assays on cell-free extracts, prepared from cultures grown with various substrates (Table 2). Apart from a low level of catechol oxygenase activity, none of the enzymes of the $\beta$-ketoadipate pathway was detected in extracts prepared from succinate-grown bacteria. Growth with either isomer of muconate resulted in the induction of muconate lactonizing enzyme, $(+)-$ muconolactone isomerase, $\beta$-ketoadipate enol-lactone hydrolase and $\beta$-ketoadipate succinyl-CoA transferase. The highest specific activities of these enzymes were always observed in bacteria grown with the cis,cis isomer. The specific activity of catechol oxygenase measured in cell-free extracts was low, and the level of this enzyme in muconate-grown bacteria was not significantly greater than in succinate-grown bacteria. However, the manometric data (Table I) show that a high rate of catechol oxidation by whole organisms is induced as a result of growth with the muconates. The discrepancy suggests that catechol oxygenase was largely inactivated under the conditions of extraction and assay which were used, but this point was not further investigated.

Table 2. Influence of the substrate used for growth on levels of enzymes of the catechol pathway in extracts from wild type P. acidivorans strain 13

\begin{tabular}{|c|c|c|c|c|c|}
\hline \multirow[b]{2}{*}{ Enzyme } & \multicolumn{5}{|c|}{ Specific activities (units/mg. protein) in extracts from cells grown with: } \\
\hline & $\begin{array}{l}\text { Succinate } \\
\text { Io } \mathrm{mM}\end{array}$ & $\begin{array}{c}\text { Cis,cis- } \\
\text { muconate } \\
\text { 10 mM }\end{array}$ & $\begin{array}{l}\text { Cis,trans- } \\
\text { muconate } \\
\text { IO mM }\end{array}$ & $\begin{array}{c}\beta \text {-Ketoadipate } \\
\text { I0 mM }\end{array}$ & $\begin{array}{l}\text { p-Hydroxy- } \\
\text { benzoate } \\
10 \mathrm{~mm}\end{array}$ \\
\hline Catechol oxygenase & 0.007 & 0.010 & 0.010 & 0.008 & - \\
\hline $\begin{array}{l}\text { Cis,cis-muconate } \\
\text { lactonizing enzyme }\end{array}$ & $<0.002$ & $0 \cdot 132$ & 0.025 & $<0.010$ & - \\
\hline $\begin{array}{l}\text { Muconolactone } \\
\text { isomerase }\end{array}$ & $<0.030$ & 0.530 & $0 \cdot 277$ & $<0.040$ & $<0.030$ \\
\hline $\begin{array}{l}\beta \text {-Ketoadipate enol- } \\
\text { lactone hydrolase }\end{array}$ & $<0.010$ & 0.194 & 0.125 & 0.062 & $<0.010$ \\
\hline $\begin{array}{l}\beta \text {-Ketoadipate succinyl- } \\
\text { CoA transferaso }\end{array}$ & $<0.010$ & 0.603 & 0.152 & 0.643 & - \\
\hline
\end{tabular}

Both enol-lactone hydrolase and $\beta$-ketoadipate succinyl-CoA transferase were induced by growth of Pseudomonas acidovorans with $\beta$-ketoadipate; there was, however, no significant induction of enzymes specific to the catechol branch of the pathway. Lastly, growth at the expense of $p$-hydroxybenzoate induced neither enol-lactone hydrolase nor muconolactone isomerase. The absence of induction of the former enzyme, essential to the metabolism of $p$-hydroxybenzoate through the $\beta$-ketoadipate pathway, is in accord with previous observations (Wheelis et al. 1967) that the species of the acidovorans group dissimilate $p$-hydroxybenzoate exclusively through meta cleavage of protocatechuate.

The catechol-oxidizing activity of Pseudomonas acidovorans involves an oxygenative ring cleavage of the ortho type. A crude, cell-free extract of muconate-grown bacteria converted catechol stoichiometrically to a $\beta$-ketoacid, identified as $\beta$-ketoadipic acid by the characteristic colour given in the Rothera reaction; the same product was produced from cis,cis-muconic acid. Highly concentrated crude extracts of bacteria grown with cis,trans-muconate, containing 20 to $30 \mathrm{mg}$. protein $/ \mathrm{ml}$, , also converted 
this isomer of muconic acid to $\beta$-ketoadipic acid. The metabolism of the cis,trans isomer therefore converges on that of the cis,cis isomer.

Properties of mutants of Pseudomonas acidovorans with blocks in the $\beta$-ketoadipate pathway. A number of mutants unable to grow with cis,cis-muconate were isolated from strain 13 of $P$. acidovorans after mutagenic treatment. Two nutritional classes were partly characterized. One class was unable to grow with either isomer of muconic acid or with $\beta$-ketoadipic acid. Analyses of cell-free extracts prepared from cultures grown for four generations in a medium containing $5 \mathrm{~mm}$-succinate, together with $5 \mathrm{mM}$ - cis,cis- or cis,trans-muconate, showed that such mutants specifically lacked $\beta$-ketoadipate succinyl-CoA transferase. The second mutant class had lost the ability to grow with muconates, but could still grow with $\beta$-ketoadipate. Analyses of cell-free extracts prepared from cultures grown on succinate and one of the muconates showed that such mutants specifically lacked $\beta$-ketoadipate enol-lactone hydrolase. Both these enzymes are, accordingly, essential for the utilization of the muconic acids.

\section{DISCUSSION}

Pseudomonas acidovorans can synthesize inducibly the enzymes operative in the catechol branch of the $\beta$-ketoadipate pathway, together with enzymes that mediate common terminal step-reactions (specifically, enol-lactone hydrolase and $\beta$-ketoadipate succinyl-CoA transferase). The regulation of the synthesis of these enzymes appears similar to that established for fluorescent pseudomonads (Ornston, I966 Kemp \& Hegeman, 1968). Catechol oxygenase is product-induced by cis,cis-muconate; both enol-lactone hydrolase and transferase (but not enzymes specific to the catechol branch of the pathway) are induced by growth with $\beta$-ketoadipate. With respect both to enzymology and to control, the pathway in $P$. acidovorans resembles the pathway in $P$. putida and $P$. aeruginosa. With respect to physiological function, however, there are notable differences. In fluorescent pseudomonads the catechol branch of the pathway provides a mechanism for the utilization of a variety of aromatic substrates. None of the aromatic substrates utilized by $P$. acidovorans is dissimilated through this sequence of reactions (Wheelis et al. 1967). Our observations suggest that in P. acidovorans (and probably in the related $P$. testosteroni) the reactions of the $\beta$-ketoadipate pathway function physiologically in the dissimilation of two non-aromatic substrates: $v i z$, the cis isomers of muconic acid. Most strains of both species grow readily with both these compounds, a capacity not found in fluorescent pseudomonads; and $P$. acidovorans can be specifically enriched from soil by the use of either cis,cis- or cis,trans-muconic acid as a sole source of carbon and energy.

Nevertheless, the induction of catechol oxygenase in Pseudomonas acidovorans elicited by the muconic acids shows that this species does possess the potential ability to dissimilate aromatic compounds through the reactions of the $\beta$-ketoadipate pathway. The physiological significance of this ability appears questionable, since no metabolic precursors of catechol are known for $P$. acidovorans, and catechol itself is too toxic and too unstable chemically to serve as a normal substrate for growth.

R. Y. Stanier was a Fellow of the J. S. Guggenheim Memorial Foundation during I967-8. We are indebted to Dr G. D. Hegeman for the provision of certain enzymes required for assays. 


\section{REFERENCES}

CÁnovas, J. L. \& Stanier, R. Y. (1967). Regulation of the enzymes of the $\beta$-ketoadipate pathway in Moraxella calcoacetica. 1. General aspects. European J. Biochem. 1, 289.

Elvidge, J. A., Linstead, R. P., Sims, P. \& ORkin, B. A. (I950a). The third isomeric (cis,trans) muconic acid. J. chem. Soc. p. 2235.

Elvidge, J. A., Linstead, R. P., Orkin, B. A., Sims, P., Baer, H. \& Pattison, D. B. (1950 b). Unsaturated lactones and related substances. Part IV. Lactonic products derived from muconic acid. J. chem. Soc. p. 2228.

HeSTRIN, S. (1949). The reaction of acetylcholine and other carboxylic acid derivatives with hydroxylamine and its analytical application. J. biol. Chem. 180, 249.

Kemp, M. B. \& Hegeman, G. D. (1968). Genetic control of the $\beta$-ketoadipate pathway in Pseudomonas aeruginosa. J. Bact. 96, 1488.

Lowry, O. H., Rosebrough, N. J., FarR, A. L. \& Randall, R. J. (I95I). Protein measurement with the Folin phenol reagent. J. biol. Chem. 193, 265.

ORnston, L. N. (I966a). The conversion of catechol and protocatechuate to $\beta$-ketoadipate by Pseudomonas putida. III. Enzymes of the catechol pathway. J. biol. Chem. 24I, 3795.

ORNSTON, L. N. (1966 b). The conversion of catechol and protocatechuate to $\beta$-ketoadipate by Pseudomonas putida. IV. Regulation. J. biol. Chem. 241, 3800.

Riegel, B. \& Lilienfeld, W. M. (1945). The synthesis of $\beta$-ketoesters by the decomposition of acylated malonic esters. J. Am. chem. Soc. 67, 1273.

Rothera, A. C. H. (1908). Note on the sodium nitro-prusside reaction for acetone. J. Physiol. 37 , 491.

Simon, E. J. \& Shemin, D. (I953). The preparation of succinyl coenzyme A. J. Am. chem. Soc. 75, 2520.

Sistrom, W. R. \& STANIER, R. Y. (1953). The mochanism of catechol oxidation by Microbacterium butyricum. J. Bact. 66, 404.

Sistrom, W. R. \& Stanier, R. Y. (1954). Enzymatic conversion of two geometrical isomers into enantiomorphs. Nature, Lond. 174, 513.

Stanier, R. Y., Hayaishi, O. \& Tsuchida, M. (195I). The bacterial oxidation of tryptophan. I. A general survey of the pathways. J. Bact. 62, 355 .

Stanier, R. Y., Palleroni, N. J. \& Doudoroff, M. (1966). The aerobic pseudomonads: a taxonomic study. J. gen. Microbiol. 43, 159.

Wheelis, M. L., Palleroni, N. J. \& Stanier, R. Y. (1967). The metabolism of aromatic acids by Pseudomonas testosteroni and P. acidovorans. Arch. Mikrobiol. 59, 302.

\section{EXPLANATION OF PLATE}

Fig. 1. Growth of Pseudomonas strains of the acidovorans and fluorescent groups on a plate containing cis,cis-muconate $(0.1 \% \mathrm{w} / \mathrm{v})$ as sole source of carbon and energy. The seven strains of Pseudomonas acidovorans $(24,29,61,62,102,129$ and 148$)$ grow well on muconic acid. Four of the nine strains belonging to the three species of the fluorescent group do not show visible growth; the remaining five strains yield isolated colonies of permeability mutants. All strain numbers are those used by Stanier et al. (1966).

Fig. 2. Growth of Pseudomonas aeruginosa strain 277 on $0.1 \%(w / v)$ cis,cis-muconate. I. The wild type. II. Permeability mutant isolated on cis,cis-muconate. III. Permeability mutant isolated on cis,trans-muconate. 


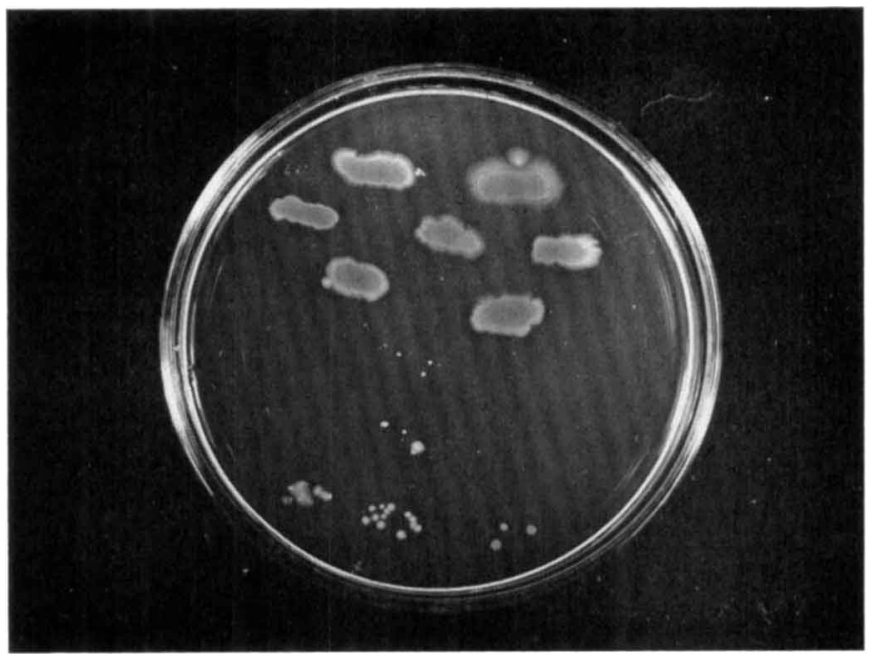

Fig. I

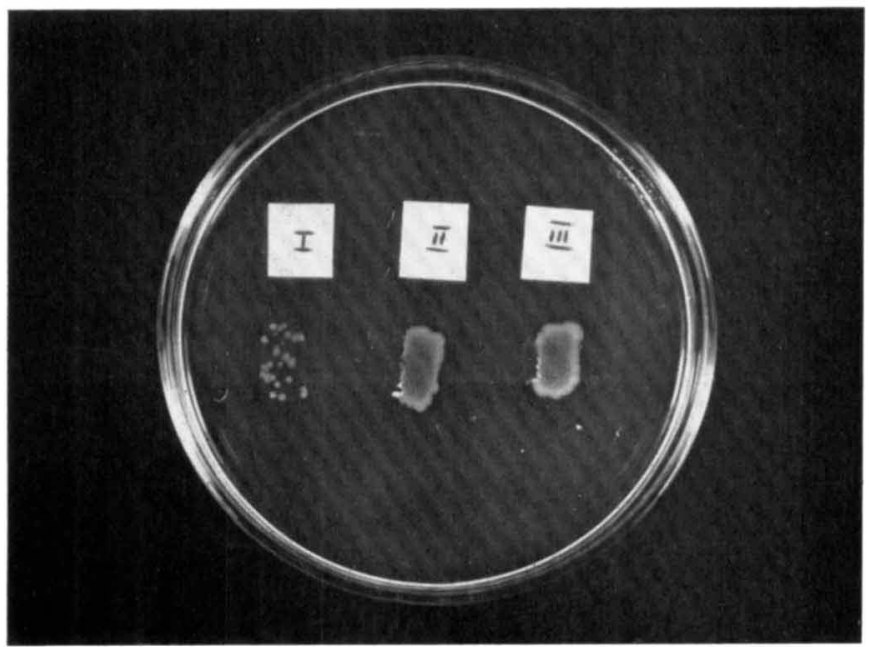

Fig. 2 